\title{
Letter to the editor: Single-incision slings for the treatment of stress urinary incontinence: efficacy and adverse effects at 10-year follow-up
}

\author{
Yu-Wei Lin ${ }^{1} \cdot$ Cheng-Yu Long ${ }^{2,3}$ (1) \\ Received: 14 April 2021 / Accepted: 8 May 2021 / Published online: 25 June 2021 \\ (C) The International Urogynecological Association 2021
}

To the Editor,

We read with interest the recent article entitled "Singleincision slings for the treatment of stress urinary incontinence: efficacy and adverse effects at 10-year follow-up" by Frigerio et al. [1]. In their study, de novo overactive bladder symptoms were assessed using clinical interviews and the answer ("leak before you can get to the toilet") to question 6 of the International Consultation on Incontinence QuestionnaireShort Form (ICIQ-SF) [2]. Both the International Continence Society (ICS) and the International Children's Continence Society (ICCS) define overactive bladder (OAB) as "urinary urgency, usually accompanied by frequency and nocturia, with or without urinary incontinence, in the absence of urinary tract infection or other obvious pathology" [3, 4].

However, the answer "leak before you can get to the toilet" to question 6 of the ICIQ-SF suggests the presence of incontinence following the sensation of urgency, but does not address the presence of isolated urgency. As such, women with a "dry" $\mathrm{OAB}$ would not be accounted for. Thus, we suggest that to assess overactive bladder symptoms, a more specific questionnaire that includes isolated urgency (i.e., the OAB symptom score) should be used.

The article also defines the subjective cure rate by using the Patient Global Impression of Improvement (PGI-I) questionnaire, with a range of responses from 1 , "very much improved,"

Cheng-Yu Long

urolong@yahoo.com.tw

1 Department of Obstetrics and Gynecology, Kaohsiung Veterans General Hospital, Kaohsiung, Taiwan

2 Department of Obstetrics and Gynecology, Kaohsiung Medical University Hospital, Kaohsiung Medical University, Kaohsiung, Taiwan

3 Department of Obstetrics and Gynecology, Kaohsiung Municipal Siaogang Hospital, Kaohsiung Medical University, Kaohsiung, Taiwan to 7, "very much worse." The PGI-I questionnaire allows us to evaluate the degree of satisfaction, but a score of 1 in the PGI-I questionnaire ("very much improved") does not address whether or not stress urinary incontinence (SUI) is cured. This does not allow us to make a distinction between women with different extents of urine leakage/incontinence. We feel that it is more clinically appropriate to define subjective cure as "no leakage on coughing, sneezing, or laughing" (i.e., the negative response to UDI-6 question 3), and "mild, acceptable leakage" (a score of 1 or 2 in PGI-I) as subjective improvement.

\section{Declarations}

Conflicts of interest The authors declare that they have no conflicts of interest.

\section{References}

1. Frigerio M, Milani R, Barba M, Locatelli L, Marino G, Donatiello G, et al. Single-incision slings for the treatment of stress urinary incontinence: efficacy and adverse effects at 10-year follow-up. Int Urogynecol J. 2021;32(1):187-91. https://doi.org/10.1007/s00192-020-04499-8.

2. Tamanini JT, Dambros M, D'Ancona CA, Palma PC, Rodrigues Netto N Jr. Validation of the "International Consultation on Incontinence Questionnaire-short form" (ICIQ-SF) for Portuguese. Rev Saude Publica. 2004;38(3):438-44. https://doi.org/10.1590/ s0034-89102004000300015.

3. Abrams P, Cardozo L, Fall M, Griffiths D, Rosier P, Ulmsten U, et al. The standardisation of terminology in lower urinary tract function: report from the standardisation sub-committee of the International Continence Society. Urology. 2003;61(1):37-49. https://doi.org/10.1016/s0090-4295(02)02243-4.

4. Austin PF, Bauer SB, Bower W, Chase J, Franco I, Hoebeke P, et al. The standardization of terminology of lower urinary tract function in children and adolescents: update report from the standardization committee of the International Children's Continence Society. Neurourol Urodyn. 2016;35(4):471-81. https://doi.org/10.1002/nau.22751.

Publisher's note Springer Nature remains neutral with regard to jurisdictional claims in published maps and institutional affiliations. 